\title{
Virality, Informatics, and Critique; or, Can There Be Such a Thing as Radical Computation?
}

\author{
Seb Franklin
}

\section{Informatics, Politics, and Theory}

Over the past two decades a substantial body of critical writing has emerged to address the broad transformations that constitute the historical period named the "society of control" (by Gilles Deleuze) and the era of the "cybernetic hypothesis" (by Tiqqun). In strictly economic terms this same period could be defined as that of computer-enabled, postFordist, neoliberal capitalism — and it should be noted straight off the bat that "computer-enabled," in the sense I intend it here, does not describe simply the rise-to-ubiquity of digital technologies in production but rather the broad array of social, economic, political, and cultural changes theorized through cybernetics research in the 1940s and both inspired and emblematized by the universal, binary, and discrete functionality of the computer. The major terms of this historical turn are by now well defined: information replaces material goods as the principle commodity; flexible, precarious forms of labor play a central role in the employment marketplace; the market, underpinned by informatic systems, regulates all social interactions; the notion of the worker as psychologically interior individual is replaced by that of the mathematically modelable automaton. While this present era is in many respects a clear extension of the disciplinary, industrial societies predicated on the familiar systems of exchange, circulation, value production, and exploitation examined by Marx in the midnineteenth century, the transformations and novel formations that define it as a distinct historical period require us to reevaluate and adapt our same principle modes of critical thought. ${ }^{1}$

This essay, which is deeply indebted to the approach set out by Luc 
Boltanski and Ève Chiapello in The New Spirit of Capitalism and taken up by Nancy Fraser in her commanding "Feminism, Capitalism, and the Cunning of History," aims to interrogate certain notions of radical political practice and the theoretical models that might be derived from them in the context of post-Fordist, neoliberal economics and the ubiquitous informatic culture that is tightly bound up with it. In her 2009 article, published in the New Left Review, Fraser uses the term "the cunning of history" to describe processes whereby historical change recasts radical practices as central to new modes of production and governance $(2009,99)$. Focusing on the changing role of second-wave feminism from the postwar, stateorganized form of capitalism to the "post-Fordist, transnational, neoliberal" form that emerged in the late twentieth century, Fraser compellingly analyses the "complex, disturbing possibility" that "cultural changes jumpstarted by the second wave, salutary in themselves, have served to legitimate a structural transformation of capitalist society that runs directly counter to feminist visions of a just society" (99).

All this is neatly summed up in an excerpt from Fredric Jameson's "Class and Allegory in Contemporary Mass Culture: Dog Day Afternoon as a Political Film," in which he examines the dialectical situation whereby social movements that campaign for an equal and just society are both structurally integral to and structurally unrealizable by late capitalism. Jameson suggests that

\footnotetext{
the values of the civil rights movement and the women's movement and the anti-authoritarian egalitarianism of the student's movement are thus preeminently cooptable because they are already-as ideals-inscribed in the very ideology of capitalism itself; and we must take into account the possibility that these ideals are part of the internal logic of the system, which has a fundamental interest in social equality to the degree to which it needs to transform as many of its subjects or its citizens into identical consumers interchangeable with everybody else. The Marxian position - which includes the ideals of the Enlightenment but seeks to ground them in a materialist theory of social evolution-argues on the contrary that the system is structurally unable to realize such ideals even where it has an economic interest in doing so. $(1977,884)$
}

I am interested in mapping the conundrum set out above, about the simultaneous co-option of radical ideals and the fundamental impossibility of realizing the basic goal of these ideals — that is, a "just society" - by late capitalism onto the current, informatic stage of the same system. For 
starters, as we will see, this informatic dimension compels us to supplement Jameson's "identical consumers" with "identical producers." Central to this argument is the way in which certain practices - ones that might seem sound as the basis for apparently radical politics when considered in terms of critical logics carried over from the Enlightenment to industrial societies - appear disconcertingly isomorphic with the fundamental principles of contemporary production when viewed through a lens of informatic critique that affords us a technically (as well as theoretically) specific analysis of the conditions of neoliberal, computational culture.

It is straightforward enough to sketch out the ways in which modes of critical thinking - from the base of Marx, Freud, and Saussure and their descendants through to the multiple theoretical approaches to identity politics that have emerged around them-have helped constitute certain modes of radical theory and practice throughout the second half of the twentieth century. In relation to Marx, to be against the dominant mode of production and circulation is to be against a normative, and thus unequal, society. In relation to Freud, to transgress norms, be they related to sex, violence, or identity, is to be against this same society. And in relation to Saussure, to be against monolithic, overarching structures and the reduction of language to pure utility is to be against this society. Each of these formations presents a model of the heroic outsider, the individual who, either alone or in a group of similar individuals, campaigns through word or deed against cultural, economic, and political injustice.

This model of individual or group resistance, which is deeply rooted in the nineteenth-century opposition between Enlightenment and Romanticism, does not contain any provision for the emergent fact that, according to Deleuze, informatic society is characterized by the elimination of notions of the individual and the group in favor of the dividual and the data bank (Deleuze 1995, 180). The dividual describes the body that is coded in terms of discrete movements (as theorized by Philip E. Agre in his "Surveillance and Capture" [1994]) or markers of identity (as theorized by Lisa Nakamura in her books Cybertypes and Digitizing Race). This discretization presents a social violence that is composed not of reactionary force but of preemptive informatics: techniques of targeting, capture, and prediction. As Samuel Weber puts it, "A certain kind of targeting defines 'opportunity' strictly in terms of the present in order to bring the future, and with it tuche $[$ luck, fortune], under control" $(2005,21)$. Further casting the Romanticist notion of explicit conflict between revolutionary indi- 
viduals or groups and the state into difficulty today is the notion that this very model of opposition is cast as a form of productive labor under the cybernetically inflected principles of game theory (which emerge from the work of John von Neumann and Oskar Morgenstern in the 1930s and 1940s and which furnish the all-against-all competition model of neoliberal economics), which state that human behavior can be most predictably modeled under the assumption of perpetual conflict or struggle.

The obvious solution to this, of course, is to locate some equivalent theoretical approaches to those set out above in practices that are specific to digital, rather than industrial, modes of production. Networking, hacking, and the virus - three of the most commonly evoked concepts of radical politics in relation to digital culture-emerge as prime candidates here. To call on but a few examples, the supposed political force of these practices can be witnessed in Ted Nelson and Howard Rheingold's presentation of hypertext and distributed communication technologies as drivers of new forms of expression and pedagogy, Critical Art Ensemble's deployment of the hacker as political activist or revolutionary, and Nathan Martins's concept of "viral activism." What this approach of substituting one group of practices for another fails to come to terms with, however, are the structural changes brought about by the emergence of a computermediated mode of production. All of the practices set out here might present modes of action specific to the computer, but they retain a connection with the Romanticist notion of the individual or group that is undercut by the predominance of the dividual and the data bank characteristic of control societies, and that places their viability as a base for effective political critique in doubt. Furthermore, by their very status as computational practices, networking, hacking, and computer viruses present the very real risk of nominally radical or oppositional acts' actually bolstering the efficacy of the mode of production by providing novel forms of aesthetic and experiential labor.

Before moving onto the virus, which poses the most complex relationship with informatic culture of the three concepts set out above, it is necessary to work through the ways in which networking and hacking, so easy to situate as modes of resistance or critique, are explicitly posited by the political and economic structures of postindustrial societies as ideal models of labor. 


\section{Networks, Hacking, and Informatic Labor}

It might be immediately noted that there is a clear difference between networking and hacking in that the former describes an organizational model while the latter describes a form of delinquency or civil disobedience. Viewed in this way it might appear that hacking, as a normatively "negative" practice, has a closer connection to civil disobedience and the computer virus than it does to the network, but to make this claim is to ignore some crucial historical facts about both practices. On the one hand, the distributed network form is as historically bound up with insurgency and guerrilla warfare as it is with the Internet, a fact that places its unequivocally "good" status in relation to contemporary liberal democracy in doubt. On the other hand, the term "hacker," as will shortly be discussed, is central to the early practice of computer science in university laboratories in the 1970s - making it very difficult to argue for the practice as unequivocally "bad" from the perspective of the current world system. If one accepts that both practices have sufficiently checkered pasts as to be indistinguishable in terms of any innate "goodness" or "badness" it becomes possible to identify some substantial points of comparison that can form the basis for an analysis that is properly suited to their specific technical character. ${ }^{3}$

The key characteristics by means of which networks and hacking can be compared, and that cast their role as oppositional practices in doubt, can be placed into two main categories. First, the network and hacking are broadly conceived of as social practices - that is, they are predicated on the intervention of human users. The most commonly raised categories through which the distributed network is proposed as a politically radical form are (1) as a general model of a nonhierarchical structure that does away with sovereign individuals and institutions and (2) as a distributed communications system that allows groups to flexibly and spontaneously organize with little formal planning. Putting aside for a moment Friedrich Kittler's challenge-one that might appear increasingly persuasive as this essay develops - that the Internet allows real communication "not between people but between machines" (Armitage 2006, 35), this makes it clear that the notion of networking as politically progressive rests on the novel types of social interaction it affords. In the same way, hacking does not describe a general condition of computer use-although as I will flesh out shortly, it once did-but rather a specific approach based on a "love" of experimenting with technology. The hacker Dr. K defines the practice 
as follows in the introduction to his collection of anonymous testimonials titled Hackers' Tales: "A hacker is motivated by a love of technology; a desire to learn, play and master the technology for its own sake, because it's fun. It's this playful desire, coupled with an intense curiosity, which leads the hacker on" $(2004,15)$. To put it another way, neither hacking nor networking can be necessarily defined through their outputs. Computer hardware will function in the same way whether it has been accessed through a software interface, elegant formalized programming, or an experimental, hacked-together approach. Equally, the appearance of a webpage is subject to the same technical standards whether it has been composed by a single individual or by a distributed group.

The difference that exists in the processes described above is not technical, located in the forms that are created by a given practice, but social, located in the way in which a form or object is produced through a given practice. This is a condition that we can trace back to one of the earliest developments toward the present informatic society, Claude Shannon's Mathematical Theory of Communication of 1948. Shannon, making a case for the kind of statistically oriented approach to formerly human-centered affairs that is characteristic of today's neoliberal economics, states:

Frequently the messages have meaning; that is, they refer to or are correlated according to some system with certain physical or conceptual entities. These semantic aspects of communication are irrelevant to the engineering problem. The significant aspect is that the actual message is one selected from a set of possible messages. The system must be designed to operate for each possible selection, not just the one that will actually be chosen since this is unknown at the time of design. $(1949,3)$

Shannon's mathematical theory foregrounds a problem that any critical theory of informatic culture must come to terms with: one of the principle impulses of post-Fordism functions to recast the social as an engineering concern. Clearly this is an ideological function rather than a material one, in that human thought and communication does not become more mechanistic but rather is presented as such—with cybernetic, cognitive-psychological, and neuroscientific approaches at the forefront. Nevertheless, a principle task of theoretical and practical critique must be to locate ways in which this computational ideology can be disrupted. The intent of a practitioner or the cultural delineation of a particular practice, be it utopian (as in the case of the network) or radical (as in the case of 
hacking), must be mediated through the technical systems that undergird this practice- the digital computer that provides both the inspiration and the means for today's indifferent, statistically modelable approach to the human that any workable critical theory must seek to analyze in terms of its contradictions and shortfalls.

The second characteristic linking networking and hacking is that both can be easily traced through empirical history to normatively "good" notions. Even taking into account the association with guerrilla tactics raised above, the notion of the nonhierarchical, utopian space of the network recurs here. The normative "goodness" of hacking may appear more problematic in light of its recent portrayal as the preserve of terrorists and cybercriminals, but etymologically the term relates to the maximization of limited ability or formal training through perseverance and experimentation. We should remember the above-cited fact that many early computer scientists self-identified as hackers. ${ }^{4}$ These two historical meanings of the noun "hacker," both of which are clearly distinct from the criminalized notion in wide use today, are set out by the "white hat" hacker and cybersecurity expert Robert Graham in his "Hacking Lexicon" (2000):

The word "hacker" started out in the 14th century to mean somebody who was inexperienced or unskilled at a particular activity (such as golf). In the 1970s, the word "hacker" was used by computer enthusiasts to refer to themselves. This reflected the way enthusiasts approach computers: they eschew formal education and play around with the computer until they can get it to work.... In much the same way, a golf hacker keeps hacking at the golf ball until they get it in the hole.

The practice that is suggested by the combination of these two aspects of networking and hacking - that is, flexible, nonhierarchical work facilitated by networked computers and proceeding through an experimental or playful approach-presents us with the seemingly paradoxical situation brought about by the centrality of play to contemporary work, a key aspect of the novel forms of value creation that characterize informatic capitalism. So both the network and hacking are social acts that are rooted in notions of coherent distributed organization and an experimental or playful approach to problem solving. Viewed in this way, they cannot be reasonably considered as the basis for radical theory or practice; rather, both present models of organization and labor that are idealized under the conditions of postindustrial, neoliberal economics. 
The very concept of play as labor presents us with an unavoidable notion in the critical analysis of informatic culture; that the digital technologies underpinning both work and play are, as Bernard Stiegler argues by borrowing a term from Jacques Derrida, pharmacological. They are at once poison and cure, allowing as much as they restrict. The analysis of networking and hacking set out above suggests that there is a layer model that can be applied to the pharmacological character of digital technologies; the freedoms they enable are confined to the social layer, to the intent of their practitioners, while the restrictions function at the layer of technical processes. This is also one of the key ways in which spectacle still performs an important role in the control society, with apparent freedoms confined to the ever-more-aestheticized graphical interface level while restrictions function at the deep structural level. Networking and hacking may present a platform for radical politics at the social level, but at the technical and infrastructural level they are emblematic of the newest forms of exploitation and restriction. Any critical theory of informatic culture must come to terms with this dual function of technology.

\section{Viruses, Automation, and Identity}

Networking and hacking appear to be practices that are opposed but in some way progressive; however, they are in fact closely linked through a common dimension that makes them unworkable as the basis for a theoretical critique. What, then, of the virus? When compared to the distributed network and hacking, the virus might appear to escape a close connection to idealized labor practices because it exhibits a more complex relationship with the social than those two practices, while suggesting a more fundamentally malicious functionality. It is also the only one of the three forms that Gilles Deleuze proposes as a "threat" to informatic control in his 1990 essay "Postscript on Control Societies," in which he draws the analogy between the virus and sabotage in the preceding era of thermodynamic, industrial labor (Deleuze 1990, 180). Despite all this, however, the virus posits some of the most significant challenges when it comes to thinking through the possibility of radical theory and practice within computation. It should be noted up front, however, that the obvious political questions surrounding the relationship between virality and post-Fordist capitalism, those concerning the role of viral marketing and viral networked content, are not of any great interest in this essay. As dis- 
cussed above, the social uses of technology, while undoubtedly of great import, do little to get at the underlying political formation of informatic societies - that is, the computer technologies that either facilitate or set the inputs and outputs of both labor and leisure practices. Viral content, be it an advertisement or some noncommercial piece of content, is a phenomenon of human users, not of technical systems - and it is these technical systems, because of the way in which they define power relations in control societies while at the same time deflecting critical analysis, that are our concern here.

To be clear, I do not suggest that the technical and the social are independent categories - that computers and networks somehow emerged outside human practices. Rather, I am concerned with the historical process whereby post-Fordism is premised on a cybernetic logic that seeks to do away with the social as such in favor of gridded, predicable mathematical models of complex systems and, as such, confine my analysis to the ways in which this logic might be responded to critically. The hypothetical example of a viral video that, while fulfilling a normatively good objective of spreading awareness of political or economic injustice, contributes to the data mine and thus the bottom line of a company such as Google or Facebook partly encapsulates the dilemma presented here. As the discussions of networking and hacking set out above demonstrate, in an era in

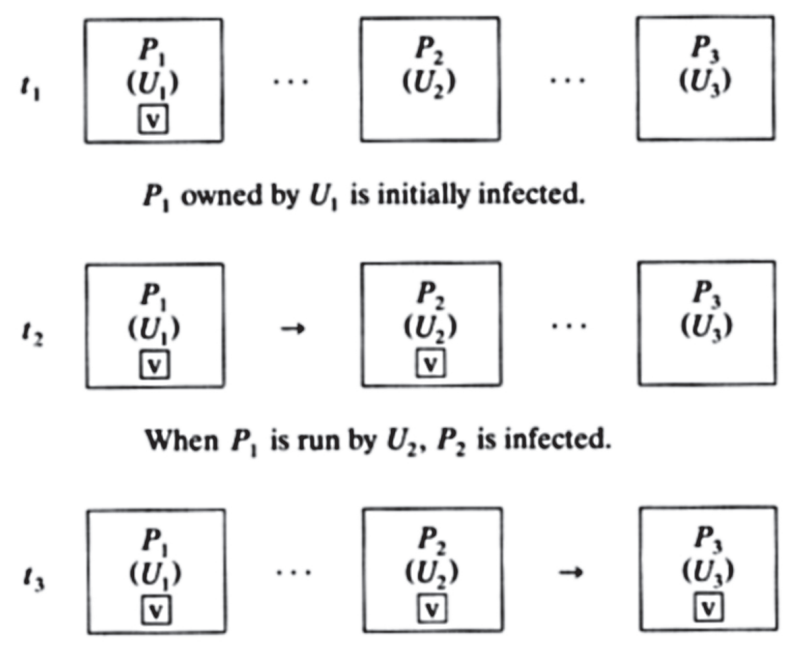

When $P_{2}$ is run by $U_{3}, P_{3}$ is infected.

FIG. 1: Virus transfer in a time-sharing system. Source: Frederick Cohen, A Short Course in Computer Viruses (New York: Wiley, 1994). 
which computation represents the material base of the mode of production, subjecting even the classical labor practices of agrarian and industrial work to the global feedback loops of a system-dynamic logic, the role of any technique that is practiced through computation requires a nuanced critical analysis that addresses the formal as political.

Despite the overwhelming associations with criminality and terrorism that are constantly attached to the notion of the computer virus there is nothing intrinsic to its technical definition that suggests the types of disruptive applications that might enable it to be posited as the basis of a resistant or oppositional politics. According to Frederick Cohen, a pioneer in the study of computer viruses, a virus need be defined no more complexly than as "a program that can 'infect' other programs by modifying them to include a, possibly evolved, version of itself" $(1994,2)$. It is specifically this characteristic that gives the computer virus its biologically oriented name. A condition of a computer virus's effectiveness is that it exists within, without necessarily impairing the functionality of, the code of the host program. Viruses are not, as Cohen notes, necessarily harmful or dangerous but simply describe programs that reproduce automatically, attaching within a host program, as a biological virus attaches itself within a host cell. If we are to accept this fundamental technical definition as primary - and in the light of the overwhelmingly technical base upon which computer-driven, post-Fordist production is premised such an approach appears essential — the virus is, at best, a politically neutral form.

If, as Cohen suggests, the technical function of the virus is absolutely neutral when it comes to its constructive or destructive potential, there nonetheless exists a substantial gap between this technical description and its cultural framing. The contrast between Cohen's view of viruses as specifically technical entities, carrying no automatic association with harm or damage, and the ones provided on the website of the Microsoft Corporation is telling in terms of the construction of viruses in relation to networked control:

Computer viruses are small software programs that are designed to spread from one computer to another and to interfere with computer operation.

A virus might corrupt or delete data on your computer, use your e-mail program to spread itself to other computers, or even erase everything on your hard disk.

Viruses can be disguised as attachments of funny images, greeting 
cards, or audio and video files.

Viruses also spread through downloads on the Internet. They can be hidden in illicit software or other files or programs you might download.

(Microsoft, n.d.; emphasis added)

This configuration of the virus as inherently disruptive, corrupting, and deceptive makes it quite clear how a certain conceptualization of such an object could find itself posited as a politically radical form. This depiction, however, has little to do with the technical form of the computer virus, which is computational and thus both formal and indifferent. As Jussi Parikka notes, "Viruses do not merely represent an example of malicious viral code but are part of a cultural-historical assemblage of digital culture.... The virus is not ... a random pattern without sense but a certain rationality" (2007, 285-86). Michael Hardt and Antonio Negri go so far as to suggest that the technical function of the computer virus is in fact isomorphic with the function of empire, stating, "Empire's institutional structure is like a software program that carries a virus along with it, so that it is continually modulating and corrupting the institutional forms around it" (2000, 197-98). So on the one hand (according to Microsoft), computer viruses are definitively disruptive, corrupting, and deceptive, while on the other (according to Hardt and Negri) they are isomorphic with the function of distributed sovereignty of which Microsoft is an economic and technological exemplar. The disparity that exists between these cultural configurations of computer viruses appears to suggest that they are so neutral as to be untenable as a political form. Furthermore, it is precisely this formal neutrality that restates the technical (if not the practical) status of viruses as an entirely separate dimension to their cultural or social appearance. As is demonstrated above in terms of the network and hacking, it is the universal and formalizing nature of the computer, in conjunction with its role at the core of contemporary production, that makes it highly problematic to claim computational practices, whatever the human intent behind them, as a model for progressive or radical theory and politics. The virus, if we are to accept only the basic technical definition of a program that replicates itself automatically, describes little more than the idealized function of computation itself, that is, a system of organization that functions automatically. ${ }^{5}$

Extending from this there is a more troubling set of concerns that surround the notion of the virus as radical political form, and that point 
toward specific historical problems around critique and identity politics in the age of ubiquitous computation. Although it takes its metaphorical name from the function of biological viruses, the automatic function of the computer virus in fact owes itself to the automatic function of its base technology, the computer. If we look back to the roots of computation, the principle mode of production in postindustrial societies, we immediately come up against the fundamental problem in the conceptualization of the computer virus as politically radical form. Alan Turing, in a seminal 1950 paper on computing machines, states that "it is the duty of the [control unit in a computer] to see that ... instructions are obeyed correctly and in the right order. The control is so constructed that this necessarily happens" (437).

Consider this automatic or necessary functionality in terms of some classical political categories: social class that functions automatically, sex and gender that function automatically, race that functions automatically, identity that functions automatically. Making these notions a reality is the dream of informatic neoliberalism. This is why we need to proceed carefully when claiming this or that cultural practice as politically radical under the material conditions of contemporary culture. To present the overall function of the computer virus as a model for contemporary critique is to place automation at the heart of progressive thought in a way that is deeply troubling, for the automatic, in the context of informatic culture, presents us with an equivalent to the notion of the natural or, to align ourselves more clearly with the critical projects of the late twentieth century, essential in relation to prior systems of inequality and domination. For natural or essential identity today we must substitute statistical identity. The fundamental power of critique lies in its activity; it is a process of unearthing contradictions and inequalities that stands in opposition to the automatic form of reading that characterizes ideology. Holding up automation as a component of radical politics thus risks returning thought around the politics of identity to a time before Marx and Freud, de Beauvoir, Butler, Said, Bhabha, Spivak, and those who followed them-or perhaps more accurately placing it in an alternate version of reality in which this work is irrelevant - at a point in history where, as Deleuze has noted, the individual and the group are replaced, in the technics and terminology of domination, by dividuals and data sets. 


\section{Noise, Addition, Boredom}

It is quite clear that one cannot take the overall function of computer viruses as a model for radical politics or critique because (1) it brings with it no essential functionality that critiques or problematizes computation and (2) a large part of its functionality is no more than a basic condition of computing applied to the reproduction of a program, creating a number of deeply unpalatable outcomes around the notion of automatic identity when applied as a model of critical thought. There is, however, one element of the computer virus that we have yet to examine-an element that is neither a simple social relation nor a simple corollary of computation itself. Viruses are not transformative but additive. The code of the computer program, or the organism in the instance of a biological virus, does not immediately begin to function in an opposite, disordered, or entropic way when a virus attaches within it, but in the same way with new information, be it a machine code, DNA, or RNA, added to it. The information previously contained within the host program is not turned into a qualitatively different entity but rather an excessive version of itself, distinguished at the level of code, but not at the level of program functionality or graphical output, through the addition or subtraction of data. When an infected program runs, more often than not it runs in its original form perfectly, with the distinction being that a separate process or set of processes runs at the same time. This additive distortion, which we can define as a quality of the computer virus that relies on automation to propagate but that does not in itself constitute automatism, offers us a route through the problem of politics and cultural theory presented by computer viruses.

This conceptual thicket can be clarified by working through the same principle of addition in relation to the closely related formation of noise, the "passive" danger to control societies that Deleuze describes as corresponding to the "active" danger of viruses $(1990,180)$. Since Shannon's Mathematical Theory of Communication and the multiple, cross-disciplinary contributions of cybernetics, noise principally appears to us as a statistically modelable component of communication, something that is "programmable and hence a mode of algorithmic rationality" (Parikka $2007,286)$. While this may hold true for a certain concept of noise that is conceptually remediated (as it is in Shannon) from a material product of electrical or electronic devices to a statistical component of a symboliclogical communication theory, it does not change the fact that noise 
describes those components of computation that exist in an unmeasurable or in-between state and thus cannot be adequately captured, coded, and cast into algorithms or grammars of action. In this conceptualization the computer virus is an example of executed noise, in that it adds new elements in a way that is not registered as a qualitative difference in the host program by any component of computer hardware. A virus attached to a cracked copy of Adobe Photoshop does not necessarily result in that copy of Photoshop running any differently from the "official" version; the virus is simply some extra code that will run in some way completely unrelated to the host program. As such, those lines of code that constitute the virus can be said to be an addition to the host program that is at once both quantitatively positive and unmeasurable. It is this aspect of the virus-the positive expression of unmeasurability - that can be productively extracted to serve as a model for radical theory and politics under cybernetic postFordism, as expressed in the work of Tiqqun and others.

In "The Cybernetic Hypothesis" Tiqqun set out the possibility expressed by additive practices that escape capture and coding as the principle form of executed unmeasurability within informatic systems:

For a cybernetician, any disorder can only come from there having been a discrepancy between the pre-set behaviors and the real behaviors of the system's elements. A behavior that escapes control while remaining indifferent to the system is called "noise," which consequently cannot be handled by a binary machine, reduced to a 0 or a 1 . Such noises are the lines of flight, the wanderings of desires that have still not gone back into the valorization circuit, the nonenrolled. $(2001,71)$

This introduces us to a fascinatingly counterintuitive principle in the theorization of informatic culture: in cybernetic societies noise is silence. Silence, in the era of informatic capitalism, is that which cannot be measured, and therefore cannot be captured, coded, transcoded, formalized, or patterned. It is notable that the 0 (or "low" signal) that makes up one half of all binary states in computation corresponds to not 0 volts but around 0.7 volts, because no physical logic gate can register a true 0 volt signal. The 1 (or "high" signal) corresponds to $2-5$ volts. In such a system, any signal between 0.8 and 2 volts prevents the gate from registering either the 0 or that 1 , of which both are crucial to the technical function of computation. This technical model of the positive yet unmeasurable or "silent" state is crucial to radical politics today. It produces noise at the fundamen- 
tal level of computability (which in this sense includes practices of informatic capture, definition, automation, modeling, and grammatization) in the same way that missing information in the compressed sound, image, or video file introduces noise to its user-readable output. It is this noise that can serve as the expression of those identities or aspects of identities that cannot be cast within predefined, normalized categories or grammars of action under post-Fordism.

Crucial to this model for radical theory and politics in the era of informatic political economy will be a set of procedures that are premised not on attacking or exceeding informatic society but on executing difference in unmeasurable and thus uncodable ways (in the historical framework deployed by Jameson and Fraser we would call these "unco-optable"), ways that cannot be computationally defined and thus cast into algorithms, grammars of action, or new modes of production. Several descriptions of such a practice can be found over the past twenty years, from Deleuze's assertion of the need for "vacuoles of noncommunication" that do not confront but "evade" $(1990,175)$ to Tiqqun's call for a politics that "comes from desires that exceed the flux insofar as the flux nourishes them without their being trackable therein, where desires pass beneath the tracking radar, and occasionally establish themselves" $(2001,72)$ and Alexander R. Galloway and Eugene Thacker's active promotion of "nonexistence" in the form of "nonexistent action," "unmeasurable or not-yet-measurable human traits," and "the promotion of measurable data of negligible importance" (2007, 135-37). Among other things, what these examples suggest is that radical theory and practice within the era of informatic or cybernetic capitalism will be boring, in the sense that it will provide us with none of the visible or audible material that we are accustomed to from prior radical practices and that allow such practices to be valorized as new forms of production. This, perhaps above all other historical impositions, poses the biggest challenge to the theorist or practitioner hanging on to the spectacular radical forms of the past, from the Romantic sublime to Bakhtin's carnivalesque, surrealism, and the various avant-gardes of the mid-twentieth century and thereafter-each of which, in the end, is based in the contestation, through sabotage and entropic excess, of the dominant modes of representation for a given era.

In the conclusion to Gender Trouble Butler asks a question that remains essential to those asked in this essay. Situated in the midst of an analysis of the way in which a multiplicity of subject positions becomes potentially 
unrepresentable, Butler's key question is italicized below:

The theories of feminist identity that elaborate predicates of color, sexuality, ethnicity, class, and able-bodiedness invariably close with an embarrassed "etc." at the end of the list. Through this horizontal trajectory of adjectives, these positions strive to encompass a situated subject, but invariably fail to be complete. This failure, however, is instructive: what political impetus is to be derived from the exasperated "etc." that so often occurs at the end of such lines? This is a sign of exhaustion as well as of the illimitable process of signification itself. It is the supplement, the excess that necessarily accompanies any effort to posit identity once and for all. $(1990,143)$

Now imagine for a moment that the "etc." in Butler's analysis, and the question that it prompts, result not from too many, or even infinite, subject positions - for today this is brutally synonymous with too many, or even infinite, target demographics, sources of valorizable activity, monetizable practices, and so on-but from the impossibility of identifying and declaring positions to define (and that can thus be exploited to produce value) in the first place. The crucial binary opposition enacted by dominant culture thus becomes that between measurable and unmeasurable. This essential modification of Butler's theory, which reformulates its key concerns to respond to informatic rather than thermodynamic societies, foregrounds the key terms for today's radical theory and practice. In contrast to all of the oppositional forms set out above, tomorrow's radical practice- which is always sadly doomed to be a computational practice according to the definition of computation dreamed of by cyberneticians and neoliberal ideologists alike and set out at the start of this essay-will be based not on contesting or even exceeding representation but rather on escaping it.

Seb Franklin is a writer and teacher based in Brighton, UK. He received his doctorate from the University of Sussex in 2010 and is currently postdoctoral research fellow in the Cultures of the Digital Economy Research Institute at Anglia Ruskin University.

\section{Notes}

1. For all the discussion of information technology, computers, and codes that it contains, Deleuze's "Postscript on Control Societies" is perhaps most notable for the conceptual proximity that it presents between control and post-Fordist, neoliberal capitalism. Throughout the piece Deleuze talks of 
wages brought into "a state of constant metastability punctuated by ludicrous challenges, competitions and seminars," "an inexorable rivalry presented as healthy competition" $(1995,179)$ and a form of capitalism that seeks to sell "services" and buy "activities" (181). It is this political-economic depiction of control, for which the computer serves as a model as much as a means of control in itself, that informs the present essay.

2. It should be acknowledged that while the members of Critical Art Ensemble celebrate the practical techniques of hacking as revolutionary in an age of ubiquitous digital information systems, they are less optimistic about the actual (call them old-fashioned) political sensibilities of hackers: "Teen hackers work out of their parents' homes and college dormitories to breach corporate and governmental security systems. Their intentions are vague. Some seem to know that their actions are political in nature. As Dr. Crash has said: 'Whether you know it or not, if you are a hacker you are a revolutionary.' The question is, a revolutionary for what cause? After poring through issues of Phrack and surfing the Internet, one can find no cause mentioned other than the first step: free access to information. How this information would be applied is never discussed. The problem of letting children act as the avantgarde of activism is that they have not yet developed a critical sensibility that would guide them beyond their first political encounter" (Critical Art Ensemble 1996, 15).

3. For more on the notions of "good" and "bad" in relation to viruses, see Parikka and Sampson 2009.

4. For an idea of the close proximity of the term "hacker" with "official," often university-affiliated programmers in the 1970s and early 1980s, see Williams 2002, especially chapters 1 and 2 and appendix B. As Williams writes, "It is a testament to the original computer hackers' prodigious skill that later programmers, including Richard M. Stallman, aspired to wear the same hacker mantle. By the mid to late 1970s, the term 'hacker' had acquired elite connotations. In a general sense, a computer hacker was any person who wrote software code for the sake of writing software code. In the particular sense, however, it was a testament to programming skill. Like the term 'artist,' the meaning carried tribal overtones. To describe a fellow programmer as hacker was a sign of respect. To describe oneself as a hacker was a sign of immense personal confidence. Either way, the original looseness of the computer-hacker appellation diminished as computers became more common" (appendix B).

5. For more on this, see Parikka 2007, 207-15.

\section{Works Cited}


Agre, Philip E. 1994. "Surveillance and Capture: Two Models of Privacy." The Information Society 10(2):101-127.

Armitage, John. 2006. "From Discourse Networks to Cultural Mathematics: An Interview with Friedrich A. Kittler." Theory, Culture and Society 23:17-38.

Butler, Judith. 1990. Gender Trouble. New York: Routledge.

Cohen, Fredrick. 1994. A Short Course on Computer Viruses. New York: Wiley.

Critical Art Ensemble. 1996. New York: Autonomedia.

Deleuze, Gilles. 1995. Negotiations. Translated by Martin Joughin. New York: Columbia University Press.

Dr. K. 2004. Hackers' Tales. London: Carlton Books.

Fraser, Nancy. 2009. "Feminism, Capitalism, and the Cunning of History." New Left Review 56: 97-117.

Galloway, Alexander R., and Eugene Thacker. 2007. The Exploit. Minneapolis: University of Minnesota Press.

Graham, Larry. 2000. "Hacking Lexicon." http://www.linuxsecurity.com/ resource_files/documentation/hacking-dict.html

Hardt, Michael, and Antonio Negri. 2000. Empire. Cambridge, MA: Harvard University Press.

Jameson, Fredric. 1977. "Class and Allegory in Contemporary Mass Culture: Dog Day Afternoon as a Political Film.” College English 38(8): 843-859.

Microsoft Corporation. N.d. "What Is a Computer Virus?" http://www. microsoft.com/protect/computer/basics/virus.mspx

Parikka, Jussi. 2007. Digital Contagions: A Media Archaeology of Computer Viruses. New York: Peter Lang.

Parikka, Jussi, and Tony D. Sampson. 2009. “On Anonymous Objects of Digital Culture." Introduction to The Spam Book. Cresskill: Hampton Press.

Shannon, Claude, and Warren Weaver. 1949. The Mathematical Theory of Communication. Urbana: University of Illinois Press.

Tiqqun. 2001. Tiqqun 2. Paris: Belles-Lettres.

Turing, Alan. 1950. “Computing Machinery and Intelligence”, Mind 49:433-60.

Weber, Samuel. 2005. Targets of Opportunity. New York: Fordham University Press.

Williams, Sam. 2002. Free as in Freedom: Richard Stallman's Crusade for Free Software. Sebastopol, CA: O’Reilly. http://oreilly.com/openbook/ freedom/appb.html 